\title{
O spatial turn: para uma sociologia do espaço
}

\author{
Martina Löw \\ Tradução do alemão e do inglês de Rainer Domschke e Fraya Frehse
}

A difusão veloz de tecnologias globais de informação e comunicação, uma progressiva divisão internacional do trabalho, a presença midiática do mundo nos espaços privados, as correntes migratórias, as mudanças climáticas globais: todos esses fenômenos são aspectos de um processo que abalou de maneira duradoura as noções de proximidade e de distância. Como observa com razão Peter Noller, a globalização conduz não apenas a uma mudança social, mas a uma mudança mental, isto é, à redefinição de conceitos e modelos que devem ajudar a entender o mundo. "O que, nos anos de 1970, se anuncia empiricamente como globalização é acompanhado por uma transição epistemológica, a passagem de uma compreensão tradicional, geograficamente limitada, para outra, pós-tradicional, aberta e plural, do espaço social" (Noller, 2000, p. 21). A percepção de que a mudança social não pode ser explicada satisfatoriamente sem uma reconceituação das categorias relativas à componente espacial da vida social é chamada de spatial turn ${ }^{1}$ (cf. Berking, 1998; Schlögel, 2003; Döring e Thielmann, 2008). Vigora cada vez mais a noção de que "'ser e tempo" não encerram toda a dimensão da existência humana” (Schlögel, 2003, p. 9), e de que o espaço é não apenas um contêiner ou uma realidade apriorística da natureza; diferentemente, ele precisa ser pensado e investigado como condição e resultado de processos sociais (cf., por exemplo, Berking, 1998; Massey, 1999; Löw, 2001; Cresswell 2004).

1. Em português, "virada espacial". Optou-se por manter, no corpo do texto, as expressões em inglês utilizadas pela autora na redação em alemão, vertendo-as para o português apenas em nota, a fim de ser fiel ao seu estilo literário (N. T.).

2. É uma alusão à obra Ser e tempo, publicada pelo filósofo Martin Heidegger em 1927 (N. O.). 
${ }^{*}$ A data entre colchetes refere-se à edição original da obra. Ela é indicada na primeira vez que a obra é citada. Nas demais, indica-se somente a edição utilizada pelo autor (N. E.).
Este texto volta-se para a questão de como, em consequência desse turn, a sociologia tem integrado o espaço em seus fundamentos teóricos, e quais as questôes investigativas atuais daí resultantes. Contraporei duas posições influentes: uma concepção materialista de espaço e outra fundada na teoria da ação. Essa comparação mostra que existe um dissenso particularmente em relação à questão de se o espaço, como condição e resultado de processos sociais, é apenas formado, ou se ele em si opera de modo estruturador. Oferecerei, então, sob a rubrica "dualidade do espaço", uma síntese das duas posições, porque estruturas espaciais e ação espacial aparecem assim como dois lados da mesma moeda.

\section{Sociologia do espaço forjada no materialismo}

Henri Lefebvre $\left([1971]^{*} 1991\right)$ é considerado um teórico dos fundamentos do espaço (cf., por exemplo, Frehse, 2013a, 2013b, no prelo). Seus trabalhos dão suporte precisamente a uma sociologia do espaço de orientação materialista, a fim de explicar a nova formação de relações de poder em consequência do spatial turn (cf. Harvey, 1989; sobre a influência que Lefebvre exerceu também na pesquisa americana sobre o espaço, cf. Shields, 1999).

O representante mais proeminente de uma sociologia materialista é David Harvey, que - com base em Lefebvre - argumenta ser o controle do espaço um mecanismo central de reprodução no capitalismo. Tal controle seria sistematicamente vinculado ao dispêndio de tempo e a recursos financeiros. Visando à especulação imobiliária, por exemplo, um fator decisivo para a obtenção do maior lucro possível é a venda no momento certo (o que implica ter o dinheiro para poder esperar). Nesse sentido, Harvey parte da ideia de que tempo, espaço e dinheiro são reciprocamente conversíveis, cabendo ao dinheiro, no capitalismo, uma função-chave. A posse de dinheiro possibilita o controle do espaço e do tempo, assim como o poder sobre o espaço e o tempo gera lucro financeiro. Eis algo que, escreve Harvey (1991, p. 158), tanto os generais como os gerentes de supermercado sabem. Com base numa retrospectiva histórica, Harvey enfatiza, assim como antes dele Lefebvre, que a economia capitalista (ou, de fato, sociedades de economia monetária em geral) gerou o espaço homogêneo e fragmentado: por meio da ciência de navegação e da cartografia, o espaço foi mapeado e homogeneizado. A partir de então, cada pedaço de espaço parece comparável a outro e, na mesma medida, passível de ser pago com recursos monetários. $\mathrm{O}$ advento do cadastro permitiu que se impusesse o direito à propriedade da terra. $\mathrm{O}$ espaço tornou-se universalmente representável. 
Ao ser produzido como fixo e fragmentado, o espaço torna-se controlável e vira mercadoria. Quem já viu um mapa-múndi produzido em outro continente rapidamente se dá conta de que todos os mapas são construções sociais. Emerge uma nova imagem diante dos olhos do observador quando de repente, por exemplo, a bota italiana figura como o centro do mundo, lá onde antes reinava o império do arquipélago indonésio (sobre a construção social de mapas, cf. Harley, 1988). Quando se afirma que o espaço é em si homogêneo e igual em qualquer lugar, os pedaços unitários repartidos podem ser comparados e vendidos como mercadorias.

Assim, o espaço não se cria a partir da vivência subjetiva, mas é contemplado quase que objetivamente a partir de uma posição externa. Nesse contexto, o lucro financeiro resulta não apenas da transformação do espaço em mercadoria, mas da superação cada vez mais rápida de espaços. Distribuir de modo cada vez mais ágil mercadorias por distâncias cada vez maiores permite um acesso cada vez mais amplo a novos mercados. "The incentive to create the world market, to reduce spatial barriers, and to annihilate space through time is omni-present, as is the incentive to rationalize spatial organization into efficient configurations of production."3 (Harvey, 1989, p. 232). É por isso que Harvey chega à conclusão de que o termo mais exato para descrever o desenvolvimento pós-moderno seria "compressão tempo-espaço" (Idem, p. 240).

Por meio de tecnologias de transporte cada vez mais rápidas e de novas tecnologias de comunicação, o mundo aproxima-se mais e mais. Harvey constata que o Estado nacional perde significado, enquanto o contrário se aplica à economia financeira internacional. Esta trabalha em prol de que o espaço perca totalmente seu significado e só o tempo conte (cf., por exemplo, Idem, p. 306).

David Harvey consegue assim instaurar uma discussão sobre o significado ou - para ser mais exata - a perda de significado do espaço em meio a condições de globalização. Se, como Lefebvre, ele enfatiza a produção social de espaços e a impossibilidade de se compreender o espaço para além das açôes (cf. Idem, p. 225), a compressão de tempo e espaço também se baseia na ideia de um substrato material chamado "espaço". Espaços diferentes como um produto da ação social num pedaço de terra permanecem impensáveis no âmbito da concepção harveyana. Pelo contrário, o autor atribui certa dinâmica própria justamente à materialidade, passível de ser comparada a uma estrutura social no sentido marxista:
3. Em português, "O incentivo para criar o mercado mundial, para reduzir barreiras espaciais e aniquilar o espaço através do tempo encontra-se tão onipresente quanto o incentivo para racionalizar a organização espacial em prol de configuraçôes eficientes da produção" (N. T.). Ver, para uma leitura em português deste livro, David Harvey, Condição pósmoderna, trad. Adail Ubirajara Sobral e Maria Stela Gonçalves. São Paulo, Loyola, 1992 (N. O.). 
4. Em português, "Argumentarei que as relaçōes espaciais e os fenômenos geográficos são atributos materiais fundamentais em todo e qualquer início de análise, e que as formas que eles assumem não são neutras com respeito aos possíveis caminhos de desenvolvimento temporal. Eles têm de ser interpretados, em suma, como 'momentos ativos' e fundamentais no âmbito da dinâmica contraditória do capitalismo" (N. T.).

5. Em português, "geografia histórica do capitalismo" (N. T.). Ver, para uma leitura em português deste livro, Edward Soja, Geografias pós-modernas, trad. Vera Ribeiro, rev. téc. Berta Becker e Lia Machado. Rio de Janeiro, Jorge Zahar, 1993 (N. O.).

6. Em português, "espacialidade", "historicalidade" e "socialidade" (N. T.).

7. No original alemão, "Gesellschaftlichkeit” (N. T.).

8. Em português, "primeiro espaço", "segundo espaço" e "terceiro espaço" (N. T.).

9. Em português, "que reconhece a espacialidade simultaneamente [...] como um produto (ou resultado) social e uma força conformadora (ou meio) na vida social" (N. T.).
I shall argue that space relations and geographical phenomena are fundamental material attributes that have to be present at the very beginning of the analysis and that the forms they assume are not neutral with respect to the possible paths of temporal development. They have to be construed, in short, as fundamental and "active moments" within the contradictory dynamics of capitalism ${ }^{4}$ (Idem, p. 33).

Harvey entende, por exemplo, a segregação residencial como um fenômeno não apenas socialmente produzido, mas que também gera relações sociais. Em sua materialização, o espaço operaria numa dinâmica própria.

Edward Soja compartilha com Harvey o fundamento marxista de uma teoria do espaço que pretende integrar o tempo ou a historicização como um de seus componentes centrais. No entanto, ele combina de maneira acentuada concepçôes marxistas com posições pós-estruturalistas. Pretendendo desenvolver uma perspectiva espaço-temporal acerca da sociedade e da vida social (cf. Soja, 1989, p. 73), o autor concebe essa visão explicitamente como "historical geography of capitalism" (Idem, p. 3). Para tanto propõe, também com referência a Lefebvre, diferenciar entre espaço como realidade dada e espacialidade como realidade socialmente produzida (cf. Idem, p. 79). A sua trialectics de spatiality, historicality e sociality ${ }^{6}$ (cf. Soja, 1996) separa espacialidade/geografia, temporalidade/história e societalida$\mathrm{de}^{7} /$ sociedade em três campos mutuamente entrelaçados. Assim, a história é sempre também um produto espacializado, a geografia uma formação que se modifica temporalmente em termos sociais, e a sociedade, estruturada espacial e temporalmente. Apoiando-se em Lefebvre, Soja (2000) diferencia entre "firstspace", "secondspace" e "thirdspace" ${ }^{8}$. O primeiro abarca as relações e práticas materializadas, as coisas no espaço. O segundo é o espaço representado, as imagens espaciais. O terceiro, enfim, é o espaço vivido que engloba os primeiros dois.

Soja sempre enfatizou também a efetividade própria do espaço. Em suas publicações ele se volta reiteradamente tanto contra a concepção de que a história aconteceria no espaço passivamente dado, quanto contra a imagem de que espaços forçam processos sociais. Em vez disso, ele pleiteia uma geografia "which recognizes spatiality as simultaneously [...] a social product (or outcome) and a shaping force (or medium) in social life"9 (Soja, 1989, p. 7).

Essa posição materialista de fundo, de que o espaço precisa ser compreendido como produto social ou atividade de criação, vem encontrando grande receptividade entre os cientistas sociais empenhados na formulação de teorias. No entanto, tem sido objeto reiterado de questionamentos ou 
críticas a suposição daí derivada, de que o espaço poderia, mediante o seu caráter estruturante, desenvolver uma força efetiva própria. Como exporei a seguir, em particular concepções forjadas na teoria da ação rejeitam de modo explícito a efetividade própria do espaço.

Sociologia do espaço forjada na teoria da ação

A teoria da ação procura pensar a ação como categoria mediadora entre os aspectos materialmente perceptíveis dos espaços e as consequências sociais das estruturas espaciais. A categoria de ação permite vincular o posicionamento físico, a percepção e as operaçôes construtivas dos sujeitos com artefatos materiais e enquadramentos institucionais. Como demonstrei na seção anterior, uma abordagem desse tipo também é um componente essencial das teorizações materialistas. No entanto, Harvey, entre outros, concentra-se mais no caráter estrutural da ação do que em observar as potencialidades dela.

Em contrapartida, o sociólogo inglês Anthony Giddens (1988) concebe, em sua teoria da estruturação, estruturas sociais que não operam de maneira rigidamente determinante, mas como meio e resultado de ações repetitivas (cf. também Bryant e Jary, 2001, p. 12). O autor compreende estruturas no sentido de regras e recursos incrustados de modo recursivo nas instituições. Nesse sentido, regras referem-se à constituição de sentido ou à sanção da ação. Elas designam os modos de operação dos processos de negociação nas relações sociais, até o nível da codificação. Sua característica estrutural é de que a sua conceituação depende do referenciamento a recursos. Estes, por sua vez, são " mídias ${ }^{10}$ através das quais o poder é exercido como elemento rotineiro da realização dos comportamentos, na reprodução social" (Giddens, 1988, p. 67).

$\mathrm{O}$ autor diferencia entre recursos alocativos - isto é, recursos materiais que resultam do domínio da natureza - e recursos autoritativos ${ }^{11}-$ ou seja, recursos simbólicos que se referem a pessoas. O caráter recursivo das estruturas pode ser mais bem exemplificado através da língua. Todos os membros de uma comunidade linguística - com algumas exceções insignificantes - usam as mesmas regras e práticas linguísticas. $\mathrm{Na}$ fala, eles reproduzem tais regras, as quais, ao mesmo tempo, lhes possibilitam falar (cf. Idem, p. 76). É o que acontece com as estruturas sociais. Estas possibilitam a ação e, então, se reproduzem novamente graças ao recurso ativo às regras de formação. "Estruturas" são conjuntos isoláveis de regras
10. No original inglês, "media" (N. T.). A opção por "mídia", aqui, difere do trecho correspondente na versão brasileira do livro de Giddens (A constituição da sociedade, trad. Álvaro Cabral. São Paulo, Martins Fontes, 1989, p. 18 ), em que o sinônimo escolhido foi "veículo" (N. O.).

11. No original inglês, "authoritative", termo que alude àquilo que tem ou procede da autoridade ( $\mathrm{N}$. T.). Trata-se de uma diferença em relação à versão brasileira do livro de Giddens (Idem, ibidem), em que o adjetivo é, no trecho correspondente (p. xxxv), traduzido por “impositivo" (N. O.). 
e recursos, por exemplo jurídicos, econômicos ou políticos. "Estrutura" designa a totalidade de estruturas diversas.

No intuito de exprimir o condicionamento mútuo entre ação e estrutura, Giddens fala na "dualidade de estrutura e ação", que ele denomina também dualidade da estrutura. O termo "dualidade" designa uma duplicidade, e não uma oposição, como ocorre no discurso sobre o dualismo. A concepção de dualidade de estrutura e ação enfatiza que "regras e recursos envolvidos na produção e reprodução da ação social são, ao mesmo tempo, os meios [media] de reprodução do sistema" (Idem, p. 70). Para o autor, as rotinas são uma categoria-chave para a compreensão dos processos sociais: "Rotinas são constitutivas tanto da reprodução contínua das estruturas de personalidade dos atores em suas açōes cotidianas, como das instituições sociais; afinal, as instituiçôes se definem como tais apenas em virtude de sua reprodução permanente" (Idem, p. 111). Seria nas rotinas que as instituiçôes sociais se produzem, e as próprias açôes se tornam hábitos. Giddens percebe as rotinas como causas do caráter recursivo da vida social. As estruturas sociais reproduzem-se recursivamente na repetição costumeira da ação cotidiana. Rotinas transmitem segurança e "a certeza de que se é [Seinsgewissheit]".

Consequentemente, o conceito de ação designa um fluxo contínuo de atividades, não uma ação intencional isolada. Enquanto o autor desenvolve a noção de rotina com base num contexto microssociológico e visando a problemas relativos à teoria da estrutura, a noção de instituição pressupõe a lógica inversa. Segundo Giddens (cf. Idem, p. 76), instituiçōes são "os traços mais duradouros da vida social". Instituiçōes são construtos que se reproduzem de maneira duradoura em rotinas.

$\mathrm{O}$ autor volta-se contra uma prática comum a vários cientistas sociais: assumir o espaço e o tempo como meras condições marginais da ação. Conforme sua argumentação, o espaço e o tempo teriam de ser conceituados como dimensões centrais da ordem. Não poderiam ser negligenciados ou tratados ao bel-prazer; ambas as categorias seriam "o cerne das teorias sociais" (Idem, p. 161).

Porém, como em sua obra o sociólogo não utiliza a noção de espaço nem de modo consistente nem constante para analisar a realidade social (cf. Werlen, 1997, p. 166), as interpretaçōes acerca das facetas teóricas do espaço variam muito nessa mesma obra (cf. também Gregory, 1989; Saunders, 1989; Urry, 1991). Numa réplica a seus críticos, Giddens (1989, p. 276) enfatiza que o espaço remete à contextualidade das interações sociais. 
Assim, ele deixa claro que o espaço se torna relevante como referência de localização na ação: portanto, não como referência geográfica ("place”), mas como "locale", ou seja, como lugar que não se define pela materialidade, mas pelo social ${ }^{12}$. Na arquitetura da teoria giddensiana da estruturação, o espaço torna-se relevante como ferramenta teórica no sentido de lugar e de regionalização no nível dos sistemas (cf. Giddens, 1988, p. 161). O autor diferencia entre estruturas e sistemas. Conceitua as estruturas como regras e recursos que permanecem no espaço e no tempo. A noção de sistema conota, para ele, o entrelaçado de ações espaço-temporais, rotinizadas ou institucionalizadas.

A própria noção de ação, Giddens só a relaciona de maneira unidimensional com o espaço: ações parecem evidentemente estar localizadas. Ele, por exemplo, não se pergunta se ações podem produzir espaço. Por sua vez, define a noção de estrutura excluindo explicitamente o espaço. "Como conjunto de regras e de recursos recursivamente organizados, a estrutura encontra-se fora do espaço e do tempo, exceto em suas realizações e coordenação como rastros da memória; e ela se caracteriza por uma 'ausência do sujeito'” (Giddens, 1988, p. 77). Enquanto Henri Lefebvre, por exemplo, mas também Pierre Bourdieu (1991) e John Urry (1991) desenvolvem uma ideia de estruturas espaciais como componentes da espacialidade dos processos sociais, a suposição de Giddens, de que estruturas seriam regras e recursos que persistem para além do espaço e do tempo, remete os espaços à concretude do espaço como lugar. Em sentido inverso, o autor tampouco se questiona sobre o espaço como produto da ação, mas sua atenção se volta para como estão equipados os "locales", para os modos da contextualidade. O espaço é, para Giddens, o lugar onde ocorrem eventos, que apresentam qualidades específicas. "Naturalmente, um mesmo recorte espacial pode ser o local para uma variedade de eventos sociais que ocorrem simultaneamente, e que são passíveis, cada um, de englobar uma multiplicidade de encontros" (Giddens, 1988, p. 124). A citação atesta claramente tanto a paralelização entre espaço e lugar, quanto a premissa de que eventos podem ser múltiplos, embora espaços diversos num mesmo lugar permaneçam impensáveis.

Nos termos de Giddens, o espaço e o tempo dividem-se em zonas por referência a práticas sociais repetitivas. Esse processo recebe o nome de regionalização. Casas seriam regionalizadas em cômodos, corredores, andares. Dia e noite ofereceriam zonas para a distinção entre períodos de sono e de trabalho. Norte e sul seriam, além de áreas geográficas, "traços sociais distintivos" (Idem, p. 174). O autor enfatiza o vínculo entre região geográfica e atribuição ou orientação sociais. Um aspecto fundamental da caracterização
12. Traduziu-se o original "Ort" "como "lugar" e "Platz" como "local". Adotou-se para "Platzierung" e "platzieren", respectivamente, "alocação" e "alocar" (N. T.). 
13. No original inglês de Giddens, "front and back regions" (N. T.).

14. Em português, "cenário" (N. T.). da regionalização seria a medida de disponibilidade de presença. Isso significa: regióes definem-se pelas possibilidades de se estar junto socialmente. Para Giddens, os fenômenos sociais estendem-se espaço-temporalmente em regiōes. Devido à sua consciência, entretanto, os seres humanos são capazes de distanciar-se disso. $\mathrm{O}$ modelo da presença/ausência também estaria na base da distinção entre regiōes de frente e de fundo ${ }^{13}$. Em todos os níveis sociais existiria uma divisão em zonas conforme o padrão "regiāo de frente" - "região de fundo", que remete ao campo de tensão entre exibição e ocultação. E isso, quer se trate da segregação de indivíduos em prisões ou instituições psiquiátricas com o objetivo de ocultá-los da sociedade e, ao mesmo tempo, impor-lhes, por meio de controle permanente, a obrigação da exibição; quer, por outro lado, se trate da divisão das cidades em regiões de frente, que são mostradas aos visitantes, e em regiões de fundo para os pobres, que são escondidas - um fenômeno já tratado pela Escola de Chicago (cf. Park et al., [1925] 1974). Essa concepção também pode ser encontrada na divisão de cômodos dos apartamentos, e ela seria observável igualmente na divisão dos corpos. Nos termos de Giddens, a regionalização do corpo em lado frontal (rosto) e traseiro encontra o seu correspondente espacial em contextos de interação. Precisamente o lado frontal, o rosto, é associado à "fachada", sugerindo que o lado frontal a ser exibido não é autêntico.

Benno Werlen $(1997,2000)$ utiliza o conceito giddensiano de regionalização para elaborar uma mudança de perspectiva na geografia, passando de uma "geografia dos objetos" a uma "geografia dos sujeitos" (Werlen, 2000, p. 611). Partindo de uma geografia que se entende como ciência do espaço, ele enfatiza que não o espaço, mas exclusivamente a ação poderia ser "o conceito-chave da representação do mundo" (Idem, ibidem). Werlen (1997) subdivide esse conceito em "ação teleológica", em ação "orientada por normas" e em ação "comunicativa ou orientada pelo entendimento mútuo". Diferentemente de Giddens, ele tematiza o espaço não apenas como "setting" ${ }^{14}$, mas como produto da ação. "Nas diferentes referências da ação também se altera a constituição do espaço - porque os relacionamentos com o corpo resultam diferentes" (Werlen, 2000, p. 612). Isso significa que, dependendo do tipo de ação, o espaço é originado de modo diferenciado. Consequentemente, o autor também tematiza o momento principal da constituição do espaço, a regionalização, em conformidade com os tipos implícitos de ação. Seguindo o diagnóstico de época giddensiano, de que as condições de vida se aproximariam "em múltiplos sentidos do tipo ideal das formas de vida espaço-temporalmente desancoradas da modernidade tardia" (Idem, p. 617) - que, 
portanto, a unidade entre espaço e construto social (por exemplo, os Estados) estaria se dissolvendo -, Werlen formula diferentes tipos de regionalização. Focando o aspecto da "regionalização produtivo-consumidora", o geógrafo se questiona a respeito das "condições e implicações globalizantes subjacentes a como os sujeitos econômicos agem no mundo cotidiano - nos lados tanto da produção quanto do consumo -, sem que tais ações já incluam o componente poder" (Werlen, 1997, p. 271). Tais relações de poder encontram o seu lugar no contexto das "regionalizações normativo-políticas". Já "regionalizações informativo-significativas", baseadas na concepção do interesse orientado pelo entendimento, enfocam as geografias da informação e, assim, o conhecimento, a vinculação emocional e a apropriação simbólica.

Em Werlen, depois do spatial turn, os espaços e as regiōes deixam de ser concebidos, de um lado, como objetos ou substâncias. Porém, de outro lado, eles tampouco são reduzidos ao caráter de signos. Já na sociologia, que por longos anos mal reparou em ordenamentos-ordens espaciais, a proposta de tematizar o espaço somente como decorrência, e não propriamente como conceito-chave, soa bem menos revolucionária do que na geografia. Por que, entretanto, limitar-se a um conceito-chave? Ou, por outra: a afirmação de Werlen oculta uma convicção profunda de que, "[e]m oposição à abordagem forjada na ciência do espaço, não se trata, na perspectiva centrada na ação, de fornecer uma explicação dos padrôes espaciais. Pelo contrário, são o processo de criação e, sobretudo, a reconstrução das decorrências regionalizantes para outros agentes que devem estar no centro dos interesses" (Werlen, 2000, p. 617).

Mas - pode-se perguntar também - será que os padrões espaciais não são tão relevantes para a análise quanto o processo de sua criação? Werlen procura compreender a(s) estrutura(s) em Giddens de modo consequente apenas por referência ao significado que ela $(\mathrm{s})$ alcança $(\mathrm{m})$ através da ação. Assim, ele pouco focaliza a potência das estruturas em possibilitar a ação (tal como demonstrado anteriormente em relação a Soja ou a Harvey). De fato, ao não pensar o espaço (também) no plano estrutural, Giddens (e, na sequência, Werlen) reproduz o dualismo entre estrutura e ação, em vez de levar adiante a dualidade dos dois aspectos. É em face disso que John Urry (1991, p. 160) sustenta o caráter duplo do espaço: "By contrast, I shall argue that time and space should be seen as produced and producing, as contested and determined and as symbolically represented and structurally organized"15.

Há muitos indícios de que os espaços não apenas são experienciados corporalmente, mas também operam retroativamente sobre os corpos;
15. Em português, "Em contrapartida, argumentarei que tempo e espaço deveriam ser considerados como produzidos e producentes, como contestados e determinados, e como simbolicamente representados e estruturalmente organizados" (N. T.). 
nesse sentido, portanto, eles são o ponto de referência ou produto da ação e ao mesmo tempo, como instituições, estruturam a ação. Renate Ruhne (2003) já demonstrou como a construção do espaço público se relaciona com a produção respectivamente da mulher insegura e do homem que se sente seguro. Tal interação tem sido estudada de modo mais abrangente por referência ao processo de etnicização. Assim, Andreas Eckert (1996) mostrou como através da política espacial colonial se produz na África uma etnicização dos corpos.

Em suma, é possível afirmar que Giddens analisa a localização da ação. Nesse sentido, ele trabalha com dois pressupostos em princípio separados, a saber: existe a ação processual e há condições espaciais, sendo que ambas precisam estar relacionadas reciprocamente - uma dedução de modo algum evidente na sociologia. $\mathrm{O}$ autor decide estabelecer essa relação no nível do edifício de sua teoria da ação que ele denomina "sistema"; portanto, unindo os dois pressupostos num entrelaçado de ações localizadas. Com o auxílio desse procedimento, Giddens consegue captar a interação entre a regionalização e a ação. Mas, como ele só tematiza o espaço como setting inserido em lugares, perde a oportunidade de servir-se de espaço e lugar como conceitos sociológicos que designam fenômenos distintos. Por exemplo, deixa de ser possível nomear a diferença entre o lugar singular e o espaço institucionalizado. Assim, permanece inexplicada a relação de um lugar específico com sua materialidade e as formas generalizáveis de regionalização. Também permanece inexplorado, por exemplo, um fato destacado por Derek Gregory (1989): como são produzidas as próprias "localities" diversas, e não apenas sua regionalização.

É verdade que Werlen busca ampliar a perspectiva giddensiana por meio de tipos de regionalização passíveis de constituírem perspectivações científicas (materialidade/economia, normas/política, assim como conhecimento/ signos). No entanto, isso lhe acarreta o problema de que também a relação entre esses aspectos permanece inexplicada, para não falar do problema de precisão na separação entre os campos.

\section{A dualidade do espaço}

Para compreender a dinâmica dos espaços, o seu caráter processual, o seu vir a ser, a sua multiplicidade, mas também a sua força estruturante, proponho ampliar a compreensão giddensiana de uma dualidade de estrutura e ação em prol de uma dualidade do espaço. Concebo espaços como ordenamentos- 
-ordens ${ }^{16}$ relacionais de seres e bens sociais em lugares. O termo ordenamento-ordem enfatiza que, primeiramente, espaços se baseiam na prática de ordenamento (como atividade de associação cognitivo-perceptiva e também como prática de alocação ${ }^{17}$ ), mas, em segundo lugar, espaços também estabelecem uma ordem já existente. Essa ordem, no sentido de estruturas sociais, tanto precede a ação como é sua consequência. Portanto, pode-se falar de estruturas espaciais quando a constituição de espaços - isto é, respectivamente, o ordenamento ou a síntese de bens ou pessoas como espaços (o reconhecimento, a associação e a intuição de ordenamentos-ordens) - está inscrita em regras e é assegurada por recursos. Sob esse prisma, estruturas políticas, econômicas ou jurídicas fazem par com estruturas espaciais (e temporais). Em conjunto, elas formam a estrutura social. Como qualquer forma de estrutura, as estruturas espaciais precisam realizar-se na ação, mas também estruturam a ação. Nesse sentido, a dualidade de ação e estrutura é também a dualidade do espaço. Isso significa que estruturas espaciais geram uma forma de ação que, na constituição de espaços, reproduz essas mesmas estruturas espaciais.

Falar de uma dualidade do espaço traz à tona a reflexão de que os espaços não existem simplesmente, mas são criados na ação, e que, como estruturas espaciais, incrustadas em instituições, guiam a ação. Em princípio, os seres humanos agem de modo repetitivo, isto é, eles se acostumam a ou aprendem rotinas que deixam suas atividades transcorrerem em percursos habituais. Não precisam refletir muito sobre qual caminho tomar, onde se alocar, como armazenar mercadorias e associar coisas e seres humanos entre si. Eles desenvolveram um conjunto de ações condicionadas pelo hábito que lhes ajudam a moldar a sua vida cotidiana. Para compreender isso de modo preciso, é útil a distinção proposta por Anthony Giddens (1988) entre a consciência discursiva - que abrange os fatos que os agentes podem expressar em palavras - e a consciência prática - que compreende o conhecimento (também no sentido corporal e emocional) que os agentes atualizam na vida cotidiana sem recorrer a processos reflexivos conscientes. A ambas as formas de consciência soma-se, na ação cotidiana, o inconsciente, motivos reprimidos da ação. A constituição de espaço ocorre, em princípio, a partir de uma consciência prática, o que se evidencia particularmente no fato de que os seres humanos raras vezes comunicam uns aos outros como criam espaços. Na constituição recíproca contínua de ação social e de estruturas sociais, os espaços surgem como resultado e precondição do decurso da ação. Em princípio, eles se baseiam em dois processos reciprocamente condicionantes: a atividade de síntese e o spacing ${ }^{18}$ (cf. Löw, 2001).
16. No original, "(An)ordnungen" (N. T.).

17. No original, "Platzierungen" (N. T.).
18. Em português, "ato de espacializar" (N. T.). 
Primeiramente, espaços surgem do fato de que os seres humanos associam elementos ativamente. Isso significa que, por meio de processos de percepção, de imaginação ou de lembrança, bens sociais e seres humanos/vivos são associados uns aos outros como espaços. Como já demonstrou Immanuel Kant ([1781] 1996), objetos/seres humanos/eventos são associados, de modo que os limites se tornam evidentes e surge uma conexão espacial a partir dos objetos individuais. Esse processo é denominado atividade de síntese.

Em segundo lugar, na maioria dos casos (com exceção do desenho arquitetônico, por exemplo), o surgimento de espaços vem de mãos dadas com alocações. Portanto, o espaço também se constitui através da alocação de bens sociais e seres humanos, ou então pelo posicionamento de marcaçóes primariamente simbólicas no intuito de identificar conjuntos de bens e seres humanos como tais (por exemplo, placas de entrada e saída de lugares). A partir de agora, denominarei esse processo spacing, que designa a atividade de erguer, de construir ou posicionar. Como exemplos podemos citar a colocação de mercadorias no supermercado, o posicionamento dos seres humanos uns diante dos outros, a construção de casas, a medição de fronteiras territoriais, a interligação em redes de computadores como espaços. Trata-se de um posicionamento em relação a outras alocações. No caso de bens móveis ou de seres humanos, spacing designa tanto o momento da alocação quanto o movimento rumo à próxima alocação. Na ação cotidiana da constituição de espaço, a atividade de síntese e o spacing ocorrem simultaneamente, já que a ação é sempre processual. De fato, as atividades de construir, de erguer ou de alocar - enfim, o spacing - são impossíveis sem a atividade de síntese - isto é, sem a associação simultânea dos bens sociais e dos seres humanos circundantes como espaços.

O que importa, para a compreensão desse conceito de espaço, é que os seres humanos associam não apenas coisas (ou seja, o mundo material), mas outros seres humanos ou grupos de seres humanos (os quais, por sua vez, interferem, eles mesmos, ativamente nos acontecimentos). Se, tal como plantas, pedras ou montanhas, os seres humanos podem ser parte de uma construção de espaço, a distinção entre espaços sociais e espaços materiais/ físicos perde o sentido.

Surgindo na ação e baseando-se em atividades de construção, os espaços são sempre sociais. São materiais os objetos que, alocados, são associados como espaços. No entanto, essa materialidade não pode ser percebida ou intuída como pura, alheia a influências ou até mesmo natural. Como seres socializados, os humanos percebem também a materialidade por meio de um 
sistema tradicional de atribuiçôes de sentido e, assim, de marcadores simbólicos. A particularidade dos seres humanos é que eles alocam a si mesmos e abandonam alocações. Além disso, influenciam as construções de espaço com mímica, gestos ou fala. Ainda que, em suas possibilidades de movimentação e de decisão, os seres humanos sejam mais ativos do que os bens sociais, seria redutor supor que bens sociais se contrapõem aos seres humanos como os objetos passivos aos ativos. Bens sociais também exercem efeitos exteriores, por exemplo em cheiros e ruídos; e dessa maneira eles influenciam as possibilidades das construções de espaço. A atmosfera torna-se, assim, uma qualidade dos espaços que não raramente resulta em inclusões ou exclusões (no sentido de estados de bem-estar ou de estranhamento específicos a tal ou qual grupo) (cf. Löw, 2008b).

Qualquer que seja o nível da constituição de espaço - tanto aquele da associação perceptivo-cognitiva quanto o das alocações -, os seres humanos não agem nem de modo individualmente singular nem de maneira amplamente idêntica. Pelo contrário, as sociedades estruturam-se em classes, gêneros, etnias ou grupos etários. Os espaços podem tornar-se relevantes de diferentes maneiras, para cada grupo social. Podem ser experimentados de modo diverso. Eles podem orientar oportunidades de acesso ou exclusões. Podem tornar-se campos de controvérsias na luta por reconhecimento. Assim, na maioria das vezes é através de constituições de espaço que se negociam relações de poder e de dominação.

Em suma, qualquer constituição de espaço se define, de um lado, pelos bens sociais e os seres humanos e, de outro, pela associação dos mesmos. Apenas quando se conhecem ambos os aspectos - isto é, tanto os “tijolos" do espaço quanto a sua relação recíproca -, há como analisar a constituição de espaço. Para a sociologia do espaço isso significa que é preciso chegar a afirmações tanto a respeito de cada um dos elementos quanto sobre o estabelecimento de relações entre eles. Outra consequência é que, em princípio, dependendo do grupo social (por exemplo, diferenciando entre crianças e adultos), é possível imaginar sínteses espaciais variadas num mesmo lugar. Então, passa a ser sociologicamente relevante enfocar também formações espaciais concorrentes num mesmo lugar.

A potência do espaço

Em resposta à questão se o espaço é sobretudo consequência da ação (Werlen), ou se ele opera socialmente como estrutura, a heurística de uma 
dualidade do espaço oferece o resultado de que, como ordenamento de potencial e de coerção, o espaço opera de modo estruturante; no entanto, tais estruturas precisam ser geradas individual e coletivamente no ato da alocação e da síntese. Nem toda alocação é formadora de estrutura, mas o próprio espaço pode ser estrutura social. Como exemplo, temos a análise de Tovi Fenster (1999) acerca da tenda dos beduínos. Na vida cotidiana, a tenda é o espaço comum da família. Quando eles recebem a visita de um estranho - e estranhos são todos os não parentes, amigos ou empregados -, cria-se de modo flexível, com cortinas, uma área para os hóspedes que fica interditada às mulheres da casa até o visitante deixar a tenda. Tal prática só pôde desenvolver-se em construções móveis dos espaços de moradia, e hoje em dia ela se encontra de tal modo rotinizada que não há mais nem como pensar na organização das relações de gênero sem essa estrutura espacial de apoio. A prática israelense de fomentar a construção de casas para a população beduína nômade conduz, nesse contexto, a dificuldades quase insuperáveis, para que o respeito ao hóspede seja conciliado com espaços femininos aceitáveis. De modo correspondente, os sentimentos dos moradores em relação à casa se mantêm, com frequência, altamente ambivalentes. A casa de construção fixa permanece por um bom tempo bem pouco prática, aos olhos da maioria dos beduínos.

Quando se fala do efeito das estruturas espaciais sobre o agregado social, sempre há o perigo de se essencializar o espaço. No entanto, partindo-se de uma dualidade do espaço, a suposição de uma interação permanente entre estrutura e ação implica que o espaço como agregado estrutural nunca gere efeitos por si só, mas dependa sempre do reconhecimento na ação (cf. também Alpsancar et al., 2011). Assim como a estrutura espacial da tenda dos beduínos somente tem efeitos sociais estruturantes por ser reconhecida como um padrão, há como encontrar exemplos nos quais as estruturas espaciais são sistematicamente ignoradas (por exemplo, quando as pessoas abandonam as vias calçadas do parque para buscar caminhos próprios ali). A consequência disso é que o espaço desenvolve o seu poder pleno quando todos os atores têm a impressão de não serem influenciados, em suas convenções, por estruturas espaciais, seguindo-as, na consciência prática, como se fossem evidentes. A regulação da ação através dos espaços ocorre de maneira eficaz quando ela pode se basear em um conhecimento preexistente já consolidado em convençōes e rotinas.

Resumindo, quis demonstrar que, mesmo enfatizando a potencialidade dos espaços, as abordagens materialistas não conseguem (e muitas vezes 
não querem) avançar conceitualmente até os espaços do cotidiano. De modo inverso, abordagens forjadas na teoria da ação conseguem informar muito acerca de lugares e atos de criação de espaços, porém sem apreender teoricamente a potência que os espaços têm de provocar ações. Reformulando a tese giddensiana de uma dualidade da estrutura, sugiro neste texto, diferentemente, uma dualidade do espaço como via conceitual de acesso ao problema. O duplo caráter do espaço - simultaneamente uma estrutura ordenadora e uma forma de ação - presta-se a uma reflexão sobre a potência dos espaços. O conceito de espaço descreve, hoje em dia, uma forma de organização da contiguidade, assim como a noção do tempo designa uma formação da sucessão. Portanto, em termos sociológicos, os espaços designam as relações entre alocações simultâneas. Esse algo alocado (também no sentido de crescido, construído, plantado) precisa aparecer no plural, a fim de ser percebido como espaço. O objeto não é espaço, mas o espaço se estende entre objetos. Por isso, espaço é noção que encarna simultaneidades.

\section{Referências Bibliográficas}

AlPSAnCAR, Suzana et al. (2011), Raumprobleme: Philosophische Perspektiven. München, Wilhelm Fink.

BERKING, Helmuth. (1998), "Global flows and local cultures: Über die Rekonfiguration sozialer Räume im Globalisierungsprozeß”. Berliner Journal für Soziologie, Berlin, 8 (3): 381-392.

BouRdieu, Pierre. (1991), "Physischer, sozialer und angeeigneter physischer Raum". In: Wentz, Martin (org.). Stadt-Räume: Die Zukunft des Städtischen. Frankfurt a. M./New York, Campus, pp. 25-34.

BRYANT, Christopher \& JARY, David. (2001), "Anthony Giddens: a global social Theorist”. In: (orgs.). The contemporary Giddens: social theory in a globalizing age. Basingstoke, Palgrave, pp. 3-39.

Cresswell, Tim. (2004), Place: a short introduction. Malden, MA, Blackwell Pub.

Döring, Jörg \& Thielmann, Tristan. (2008), Spatial turn: Das Raumparadigma in den Kultur- und Sozialwissenschaften. Bielefeld, Transcript.

ECKERT, Andreas. (1996), “'Unordnung' in den Städten: Stadtplanung, Urbanisierung und koloniale Politik in Afrika". In: Rothermund, Dietmar (org.). Periplus: Jahrbuch für außereuropäische Geschichte. Münster, Lit, pp. 1-20.

FEnSTER, Tovi. (1999), "Space for gender: cultural roles of the forbidden and the permitted”. Enviroment and Planning D: Society and Space, 17: 227-246.

FreHSE, Fraya. (2013a), “Zeiten im Körper: Der Beitrag der Lefebvre’schen Me- 
thode für die (lateinamerikanische) Stadtforschung”. In: HuFFSCHMID, Anne \& WILDNER, Kathrin (orgs.). Stadtforschung aus Lateinamerika. Bielefeld, Transcript Verlag, pp. 145-169.

. (2013b), "Os tempos (diferentes) do uso das Praças da Sé em Lisboa e em São Paulo”. In: Fortuna, Carlos \& Leite, Rogerio Proença (orgs.). Diálogos urbanos: territórios, culturas, patrimónios. Coimbra, Almedina, pp. 124-173.

(no prelo), "In search of difference 'in and through' São Paulo: the regressive-progressive method". In: MoravÁnsKy, Akos, SCHMid, Christian \& STANEK, Lukasz (orgs.). After the urban revolution: applying Henri Lefebvre in urban research and architecture. London, Ashgate.

GIDDENS, Anthony. (1988), Die Konstitution der Gesellschaft: Grundzüge einer Theorie der Strukturierung. Frankfurt a. M./New York, Campus. . (1989), “A reply to my critics”. In: HeLD, David \& ThOMPSON, John (orgs.). Social theory of modern societies: Anthony Giddens and his critics. Cambridge, Cambridge University Press, pp. 249-302.

Gregory, Derek. (1989), "Presences and absences: time-space relations and structuration theory". In: Held, David \& THOMPSON, John (orgs.). Social theory of modern societies: Anthony Giddens and his critics. Cambridge, Cambridge University Press, pp. 185-214.

Harley, John Brian. (1988), “Maps, knowledge and power”. In: CosGrove, Denis \& DANIELS, Stephen (orgs.). The iconography of landscape: essays on the symbolic representation, design and use of past environments. Cambridge/New York, Cambridge University Press, pp. 277-313.

Harvey, David. (1985), The urbanization of capital. Oxford, Blackwell. . (1989), The condition of postmodernity. Oxford, Blackwell. . (1991), "Geld, Zeit, Raum und die Stadt". In: Wentz, Martin (org.). Stadt-Räume: Die Zukunft des Städtischen. Frankfurt a. M./New York, Campus, pp. 149-168.

KanT, Immanuel. ([1781] 1996), Kritik der reinen Vernunft. Frankfurt a. M., Suhrkamp.

Lefebvre, Henri. ([1971] 1991), The production of space. Oxford, Blackwell.

Löw, Martina. (2001), Raumsoziologie. Frankfurt a. M., Suhrkamp. (2008a), Soziologie der Städte. Frankfurt a. M., Suhrkamp. (2008b), "The constitution of space: the structuration of spaces through the simultaneity of effect and perception”. European Journal of Social Theory, Sussex, 11 (1): 25-49.

MASSEY, Doreen. (1999), Power-geometries and the politics of space-time: Hettner-lecture 1998. Heidelberg, Verlag der Universität Heidelberg. 
NOLLER, Peter. (2000), “Globalisierung, Raum und Gesellschaft. Elemente einer modernen Soziologie des Raumes". Berliner Zeitschrift für Soziologie, Berlin, 1: 21-48.

PARK, Robert Ezra et al. ([1925] 1974), The city. Chicago, University of Chicago Press.

RuHne, Renate. (2003), Raum Macht Geschlecht: Zur Soziologie eines Wirkungsgefüges am Beispiel von (Un)Sicherheiten im öffentlichen Raum. Leske, Opladen.

SAUNDERS, Peter. (1989), "Space, urbanism and the created environment". In: HeLD, David \& THOMPSON, John (orgs.). Social theory of modern societies: Anthony Giddens and his critics. Cambridge, Cambridge University Press, pp. 215-235.

SCHLÖGEL, Karl. (2003), Im Raume lesen wir die Zeit: Über Zivilisationsgeschichte und Geopolitik. München, Carl Hanser.

SHIELDS, Rob. (1999), Lefebvre Love \& Struggle: spatial dialectics. New York, Routledge. SOJA, Edward William. (1989), Postmodern geographies: the reassertion of space in critical Social theory. London, Verso.

(1996), Thirdspace: journeys to Los Angeles and other real-and-imagined places.

Oxford, Blackwell.

. (2000), Postmetropolis: critical studies of cities and regions. Oxford, Blackwell.

URRY, John. (1991), “Time and space in Giddens social theory”. In: BRYANT, Christopher \& JARY, David (orgs.). Giddens' theory of structuration: a critical appreciation. London, Routledge, pp. 160-175.

Weber, Max. ([1920] 1972), Gesammelte Aufsätze zur Religionssoziologie. Tübingen, Mohr.

Werlen, Benno. (1997), Sozialgeographie alltäglicher Regionalisierung. Stuttgart, F. Steiner.

(2000), "Alltägliche Regionalisierungen unter räumlich-zeitlich entankerten Lebensbedingungen". Informationen zur Raumentwicklung, Bonn, 9 (10): 611-622.

\section{Resumo}

O spatial turn: para uma sociologia do espaço

Este artigo tem como objetivo conferir plausibilidade ao conceito sociológico do espaço como disposição relacional de seres e bens. Como os processos da globalização também interferem nos modos de vivenciar o espaço, a Sociologia vê-se obrigada a repensar sua conceituação. Em termos metodológicos, oporemos duas posiçôes contrárias: teoremas materialistas que partem da estrutura espacial, de um lado, e abordagens orientadas na prática e que partem da ação, de outro. Como conclusão, com referência à teoria da estruturação de Anthony Giddens, apresentamos a proposta de uma síntese das duas abordagens. Dessa forma, torna-se possível uma teoria do espaço que não atribui ao espaço forças essencialistas, nem o reduz a meras sequências de ação.

Palavras-chave: Espaço; Ação; Estruturas; Atmosferas; Globalização. 


\section{Abstract}

After the spatial turn: for a sociology of space

The aim of this article is to lend plausibility to the sociological concept of space as a relational disposition of beings and goods. Since globalization processes also interfere in people's ways of experiencing space, Sociology has been forced to rethink its conceptualizations. In methodological terms, I juxtapose two contrary positions: materialist theorems that set out from spatial structure, and practice-oriented approaches that set out from action. Citing Anthony Giddens's theory of structuration, I conclude by proposing a synthesis of these two approaches. This allows us to develop a theory of space that neither attributes it with essentialist forces, nor reduces it to a mere sequence of actions.

Keywords: Space; Action; Structures; Atmospheres; Globalization. 